

\title{
COVID-19 Impacts on High Education: Virtual Learning Challenges on University of Prishtina
}

\author{
Bujar Bajçinovci ${ }^{1}$, Mimoza Dugolli ${ }^{*}$ \\ ${ }^{1}$ University of Prishtina, Faculty of Architecture, Kosova. \\ Email:bujar.bajcinovci@uni-pr.edu,mimoza.dugolli@uni-pr.edu
}

\begin{abstract}
$\underline{\text { Abstract: }}$
The cease of the high educational institutions in Kosova, as a result of the preventive measures against the spread of Covid-19 has high causatum on the traditional system of academia, moreover, as we evidence later the global preventive measures has affected the all education systems in the world. Hence, there was a new kind of felling, with new immediate responsive state caused by the change of learning patterns. While this eminent experience of shifting from traditional learning to virtual learning domain has result with immediate quarantine in Kosovo, and new style of living, new experience of education, and a new teaching interaction with students, especially in the faculty of the architecture, University of Prishtina, where both authors teach. The comments presented in this paper investigated the COVID-19 phenomenon in University of Prishtina, Kosova, from pedagogue point of view, where to many learning habits and teaching methods are being radically changed in the front of new contagious disease. Focusing on the architectural design teaching methods, public health, students, high education, and possible students' depressions related to the quarantine conditions. As history are repeating with tremendous global plagues, how we came in this situation in first place, nowadays! Affecting the entire globe academia's in a month-s! From the middle of the March, when new Public Health measures has been started, students and teachers of University of Prishtina has reacted with great awareness and teaching discipline, thus, contributing to the virtual academic system, hence, participating in summer semester with 18,465 online students, and 1,405 teaching staff. Moreover, University of Prishtina, has never had this virtual mobilization as a teaching technique, but never seeing this discipline before. The current, and possible future state of virtual learning in academia of Kosovo, are as the pandemic situation of academia globally.
\end{abstract}

Key words: COVID-19, Virtual Learning, Academia, University of Prishtina, Architecture.

\section{INTRODUCTION}

The cease of the high educational institutions in Kosova, as a result of the preventive measures against the spread of Covid-19 has high causatum on the traditional system of academia, moreover, as we evidence later the global preventive measures has affected the all education systems in the world. Hence, there was a new kind of felling, with new immediate responsive state caused by the change of learning patterns. While this eminent experience of shifting from traditional learning to virtual learning domain has result with immediate quarantine in Kosova, and new style of living, new experience of education, and a new teaching interaction with students, especially in the faculty of the architecture, University of Prishtina. "In the continuum 
of evolution and adaptation of living organisms, ranging from microorganisms to human beings, there are certain cycles of time that carry with its cardinal changes that human beings must face and find the best possible public health solutions. The daily challenges must stimulate new scientific research and crucially need to be directed at utilizing all academia resources." [1]. The new situation of global public health state is crystal clear, and, finally we are aware, that the World is one truly Ecumenopolis, where problems and solutions are interlinked wide holistically, moreover, health solutions emphasizes the need to create efficient global health strategies reflecting to the World as a one big city. [2] "Therefore, we have come into a situation where a number of questions need to be raised about the necessity of redefining many daily life habits... There are certain difficulties and limitations in not implementing natural and evolving design strategies conditional on new lifestyles, technological development, globalization and redefining the phenomenon of design values up to now. Architectural design faces major challenges, as a result of evident climate change, as well as completely new lifestyles" [3], and, new situation with preventive measures of this pandemic. The new teaching methods of academia emerge a new approach to holistic phenomenon's emphasizes the need to create harmony between the need for functional teaching system and the rational academic actions expressed for situations and environments. The traditional practice of teaching methods never will be the same, and must evolve from only-way or sequential nature of teaching process to something new, which we all somehow know of virtual learning, but, never fully experienced! We are witnessing the urgent need to address teaching, social and economic issues, while at the same time experiencing the global health hazard [1].

\section{MATERIALS and METHODS}

The comments presented in this paper investigated the COVID-19 impacts in University of Prishtina in Kosovo, from pedagogue point of view, where to many teachings, learning habits, and lifestyle are being radically changed in the front of new contagious disease. Focusing on the academia, virtual learning, students, high education, and possible students' depressions related to the quarantine conditions. The comments consist of empirical observation through university data, interviews, government documents, and literature review. In order to perceive a clearer data, the observation is made within architecture faculty, municipality actions, focusing on the environment and the academia campus. [2] The data collected include data, composition of student design projects, attributes of the teaching methods, dimensions of the 
curricula. The additional data for this paper is based on the right understanding of legacy for future generations, which consists in the fact that we are interdependent with the demand for public health wellbeing and the empowerment of possible alternatives in preserving the ecosystem for the future. [2] "Therefore, the approach and thinking that this phenomenon will not happen to another generation rather than the current one, creates a false reality, as the entire ecosystem is in direct interaction and dependence of past, present, and the future".[4]

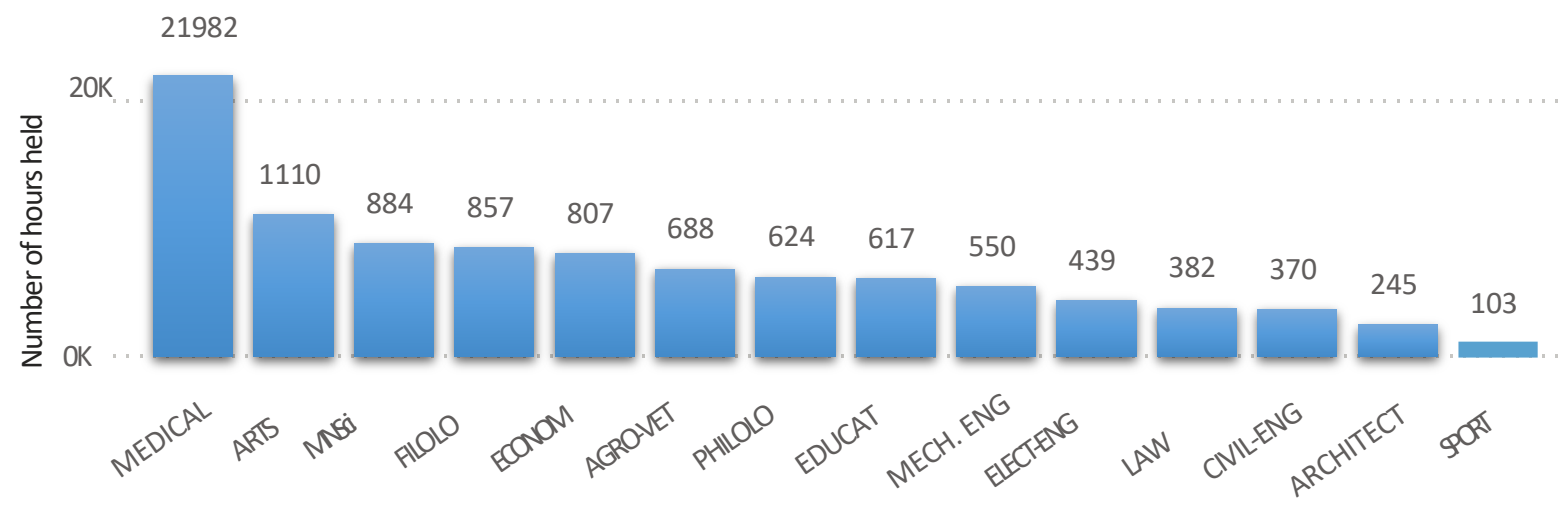

Figure 1. University of Prishtina, number of hours taught by Academic Units. (July 1, 2020) Source: University of Prishtina, Office of Information Technology [7]

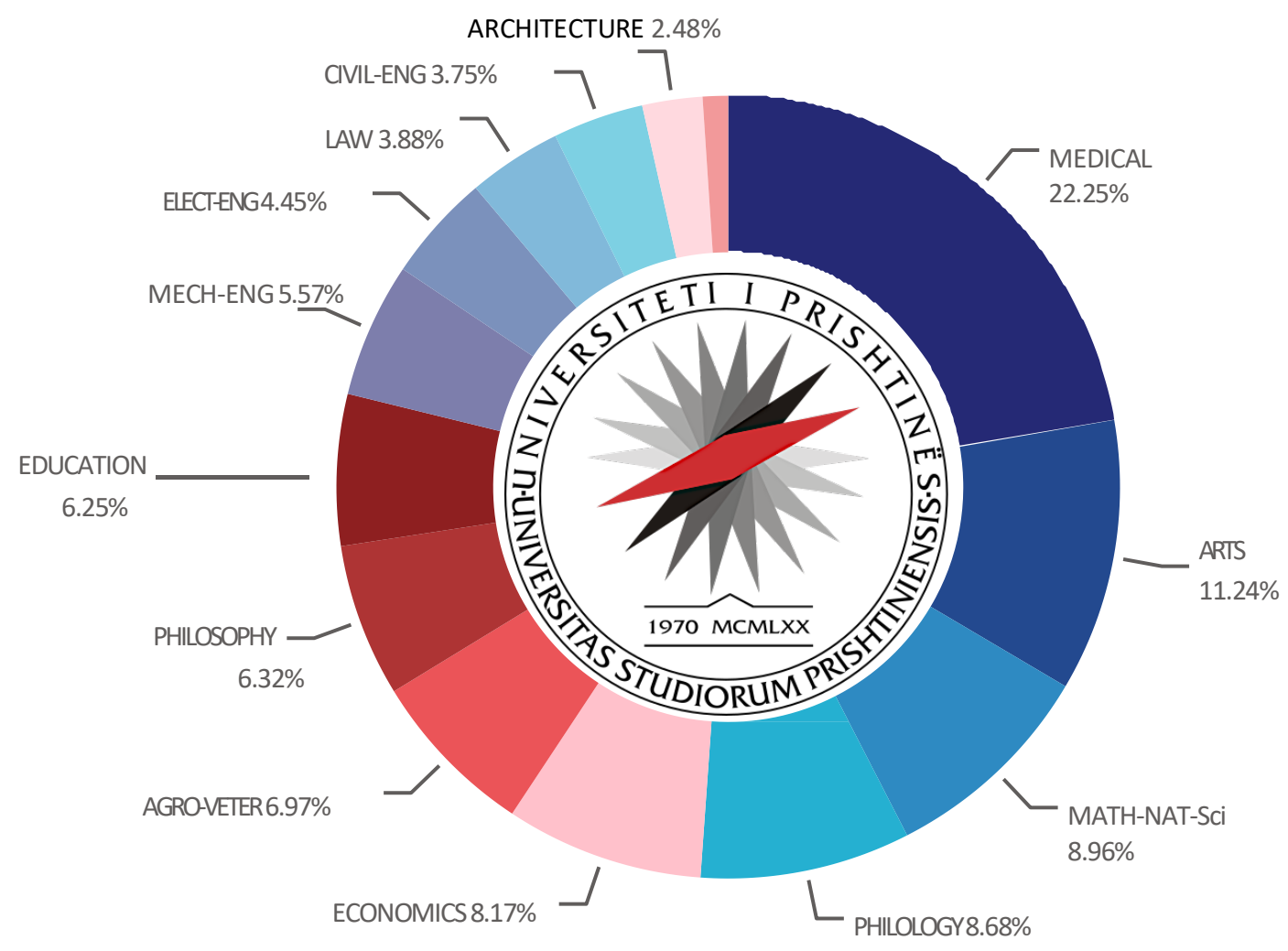

Figure 2. University of Prishtina, percentage in teaching according to Academic Units. (July 1, 2020) Source: University of Prishtina, Office of Information Technology [7] 
The trend of globalization is an unstoppable historical process that will reflect on new technologies, science and evolutionary teaching strategies. [1]. The feeling that we belong to something, as part of the umwelt, and whole universe, these are the elements and features of the new implementation of global wellbeing, as well as World public health. The new millennium will bring fundamental life, and health situations, which call into question the necessity of redefining many our habits, and lifestyle! [2]

Table 1. COVID-19 cases: Globally, Kosova, and Albania. (July19, 2020) Source: National Institute of Public Health of Kosovo [5, 6]

\begin{tabular}{l|c|c|c} 
COVID-19 & Infected & Healed & Deaths \\
\hline World & & & \\
\hline Kosovo & $14,311,886$ & $8,044,178$ & 602,757 \\
\hline Albania & 5617 & 2811 & 130 \\
\hline
\end{tabular}

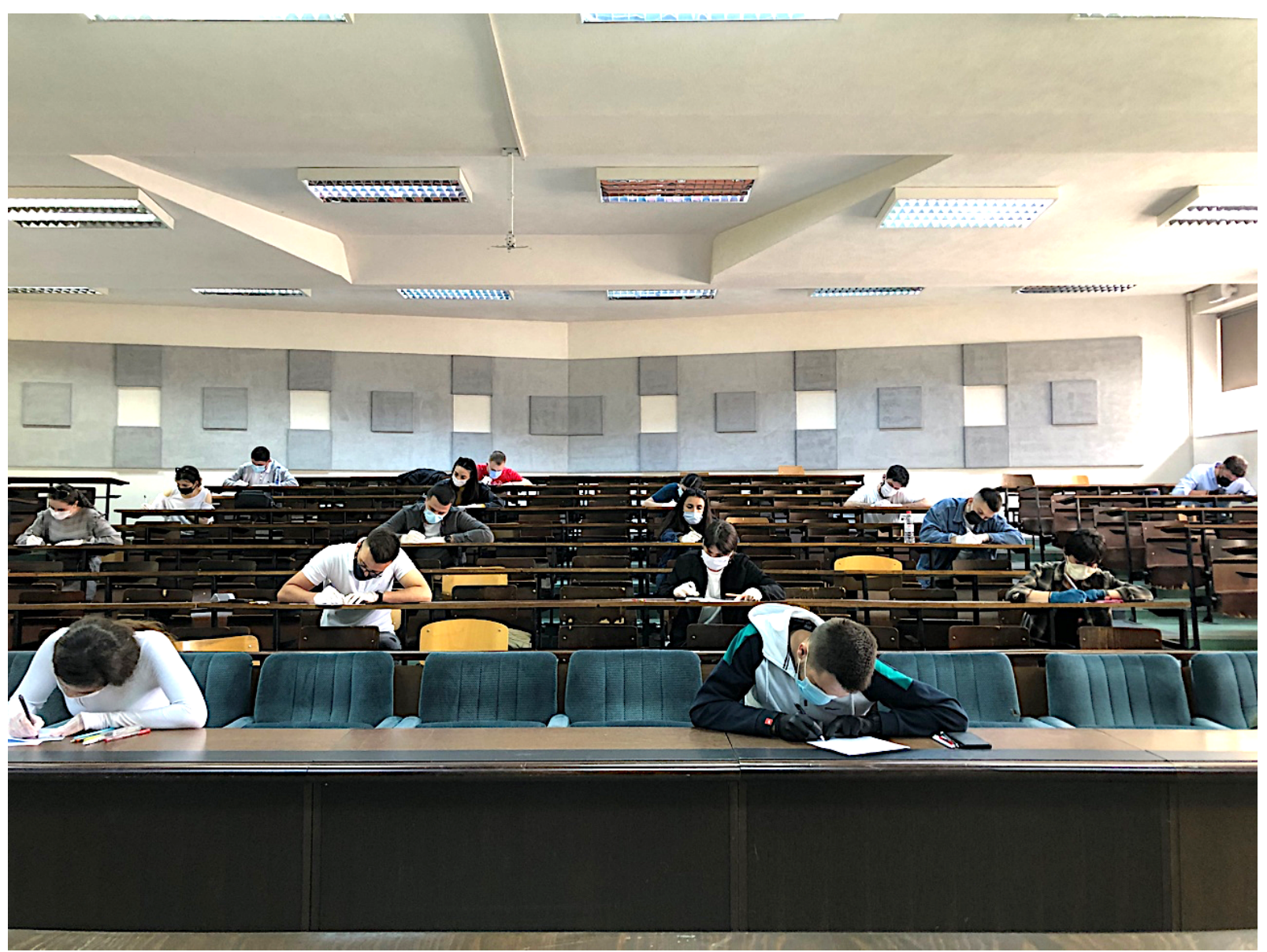

Figure 3. University of Prishtina, Architecture, final exam in Architectural Design 4 course. (June 17, 2020) Source: Authors, June 2020. 


\section{DISCUSSION}

Since the middle of the March, Kosovo has taken the most necessary health measures, such a quarantine, for the infected individuals, districts, and specific cities. Those measures have been backed up from the awareness of the modest capacities of health care system service, to treat this specific disease. Completely new situation in medication knowledge, and with great impact on Kosovar academia, especially in the University of Prishtina with 42,006 students. [2] Infection with SARS-CoV-2, the virus that causes COVID-19, can cause disease ranging from mild to severe, and in many cases can be fatal. Symptoms usually include fever, cough, and difficulty breathing. The disease may be manifested by other symptoms such as those of gastrointestinal infection. Also, the person may be asymptomatic but infected with COVID-19. According to the WHO and the CDC, COVID-19 symptoms may appear from 2 to 14 days after exposure $[2,5,6]$. Architectural studies have always been a pioneer of social change based on what is called modern and having the role of Avant Garde futuristic premises. In terms of comfort and quality of life the design process will strive to find the best possible solutions to the specific architectural problem, when new real-life functions are required. As never before, today we have experiencing multidimensional challenges with e great impact on public health, that are subject of the new health situations. [1] University of Prishtina, where we booth teach, have 42,006 students, and 900 members of the academic staff. This unity of academia in virtual teaching, have started with a great enthusiasm without prior online teaching practice. Finally, the spring semester have been completed with great students results, as per opinion of the authors. Moreover, we have evidenced a boost of academic affection and great efforts from Kosovar students to overcome this pandemic situation, and finally to breakthrough this nightmare situation!

\section{CONCLUSION}

The current and possible future state of Public Health in Kosovo are as the pandemic situation of Balkan States. Regarding to the academia, the students of the University of Prishtina concluded the academic year 2019/2020 differently than other times. Due to the situation created by the COVID-19 pandemic, they finished the semester on the "Google Meet" platform and not as in the past, in the faculty classrooms. This virtual way of learning came after the decision of the UP management to protect students and staff from coronavirus. From the beginning of the application of this form of virtual teaching there was 98,475 online lectures held at the University of Prishtina 
"Hasan Prishtina" [8], and we have evidenced a boost of academic affection and great efforts

from Kosovar students, and teaching staff to overcome this pandemic situation.

\section{REFERENCES}

[1] Bajçinovci, B. (2016). Sustainable Architectural Design - Principles - In the Albanian Language. Journal of Science, Humanities and Arts. Volume 4, Is. 3. DOI: 10.17160/josha.4.3.306

[2] Bajçinovci, B., Bajçinovci, M. (2020). COVID-19 in Kosovo: Point from an Urbanite. Journal of Science, Humanities and Arts. Volume 7, Is. 3. DOI: 10.17160/josha.7.3.685

[3] Bajçinovci, B., Jerliu, F. (2016). Challenges of Architectural Design in relation to Environment and Air Pollution. A Case study: Prishtina's first public parking garage. Journal of Science, Humanities and Arts. Volume 3, Is. 7. DOI: 10.17160/josha.3.7.254

[4] Bajçinovci, Q. B., Bajçinovci, B., Bajçinovci, U. (2020) Architectural Design Process: Consulting with Nature. Journal of Science, Humanities and Arts. Volume 7, Is. 2. DOI: 10.17160/josha.7.2.643

[5] National Institute of Public Health of Kosovo. (2020)

[6] RKS. Ministry of Health, National Institute of Public Health of Kosovo. (2020). Temporary Guidelines of Measures for Prevention and Fighting Covid-19 In Public and Private Institutions.

[7] University of Prishtina, Kosova. Office of Information Technology (2020). https://app.powerbi.com/view?r=eyJrljoiMDBkNWMzY2EtMGVhZC00YWMwLTk2 MDYtNjk0MWZhMmE1MTRIIiwidCI6ImMwMzRjM2I0LWQwMmItNDM2MS04M2 YwLTNiMWI5ZWE0MzcwYyIsImMiOjh9

[8] University of Prishtina, Kosova. (2020). https://www.uni-pr.edu/page.aspx?id=2,4,1144 